\title{
Impact of Individual and Neighborhood dimensions of Socioeconomic Status on the Prevalence of Mild Cognitive Impairment over Seven-Year Follow-Up
}

\author{
Miguel A. Fernández-Blázqueza , Bárbara Noriega Ruiza, Marina Ávila-Villanueva ${ }^{a}$, \\ Meritxell Valentí-Soler ${ }^{\mathrm{b}}$, Belén Frades-Payo ${ }^{\mathrm{a}}$, Teodoro Del Ser ${ }^{\mathrm{b}}$, Jaime Gómez-Ramírez ${ }^{\mathrm{c}}$ \\ ${ }^{a}$ Neuropsychology Department, CIEN Foundation \\ ${ }^{b}$ Neurology Department, CIEN Foundation \\ ${ }^{c}$ Neuroimaging Department, CIEN Foundation \\ E-mail: mafernandez@fundacioncien.es
}

\begin{abstract}
IMPORTANCE: There is strong evidence about the association between low socioeconomic status (SES) and higher risk of dementia. However, it has not been conveniently addressed so far the role of SES on the incidence of Mild Cognitive Impairment (MCI) which is considered a prodromal stage of latter dementia. OBJECTIVE: To examine the impact of individual and neighborhood dimensions of SES, as well as their interaction, on the risk of developing MCI in a sample of older adults that were followed-up for seven years. DESIGN, SETTING, AND PARTICIPANTS: Data from the Vallecas Project cohort, an ongoing community-based longitudinal study for early detection of cognitive impairment and dementia, were used to build two indices of SES namely individual and neighborhood, as well as a global SES as a combination of both, and to investigate their effects on MCI conversion by means of a multivariate-adjusted Cox proportional hazard model. MAIN OUTCOMES AND MEASURES: Based on data referred to as individual-level (one's educational attainment, occupation, parent's level of education) and neighborhood-level (district's income, unemployment rate, housing price, percentage of people with no formal qualifications, with higher education, and with white-collar employs) different composite measures of SES were built and quartiles were considered for further analyses. MCI diagnoses were agreed between neurologists and neuropsychologists at consensus meetings. RESULTS: 1180 participants aged 70 years and older were enrolled in this study (mean age at baseline, 74.9 years; $63.5 \%$ females). Of these, 199 cases of MCI (16.9\%) were diagnosed at any point of the follow-up. The individual and neighborhood dimensions of SES played different roles in the dynamics of the MCI occurrence through ageing. Most importantly, the risk of developing MCI was almost double for lower SES quartiles when compared to the highest one. CONCLUSIONS: The incidence of MCI in older adults was related to both individual characteristics and socioeconomic context. Public health strategies should be holistic and focus not only on promoting the classical individual preventive measures, but also on reducing social inequalities as a means of fostering healthy ageing and reducing dementia burden.
\end{abstract}

\section{INTRODUCTION}

In the last years social phenomena have been incorporated into the scope of neuroscience, especially neuroepidemiology, to better explain individual behavior, dysfunction and disease. The socioeconomic status (SES), that was a mere covariate in statistical analyses, has become a topic of interest for researchers in its own right (Farah, 2017). SES is a complex construct that reflects the overall position in the society 
of a person. Thus, SES is often operationalized as a combination of education, occupation, income, and other related familiar and neighborhood characteristics such as exposure to violence, pollution, parental and health care or cognitively stimulating environment (Krieger, Williams, \& Moss, 1997). From the perspective of the public health, understanding how SES interacts with both healthy and pathological human development is a crucial issue.

Although in general terms SES could be conceptualized as a continuum from worst to best off in which those who are better off have access to more material and non-material resources, SES is typically divided into levels to refer to the places where an individual can be situated (e.g. quintiles, quartiles, etc.). The utility of SES lies precisely in its ability to place a person in a continuum in relation to the others. Thanks to this, it has been possible to analyze the role of SES as a predictor in a broad range of health variables. In particular, higher SES have been associated with lower rates of some physical conditions such as coronary disease, diabetes, stroke, cancer, and arthritis (Adler \& Stewart, 2010), or psychiatric illnesses such as depression or anxiety (Kessler et al., 2005; Lorant et al., 2003). Regarding cognition, it has been demonstrated an association between SES and cognitive performance in adults across lifespan, independent of individual demographic and health characteristics (Besser, McDonald, Song, Kukull, \& Rodriguez, 2017; Lorant et al., 2003; Weng et al., 2018). There has also been evidenced an association between SES and the incidence of dementia (Cadar et al., 2018; Nakahori et al., 2018), as well as with mortality (Åberg Yngwe, Kondo, Hägg, \& Kawachi, 2012; Russ et al., 2013; van de Vorst, Koek, Stein, Bots, \& Vaartjes, 2016). However, it has not been conveniently addressed so far the role of SES on the incidence of Mild Cognitive Impairment (MCI) which is considered a prodromal stage of latter dementia (Jack et al., 2018; Petersen, 2004).

Socioeconomic factors could affect health at different times in the lifespan, at distinct levels (e.g. individual, familiar, or area-based), and through different causal pathways (e.g. by determining exposures, vulnerability, or direct physiological effects) (Braveman et al., 2005). In research practice SES is often indirectly estimated in terms of individual factors, specifically education and occupation, or in terms of area-based characteristics such as the context or the neighborhood in which a person lives. Therefore, two dimensions of SES namely individual SES (ISES) or neighborhood SES (NSES) could be differentiated according to some nuances.

The main aim of the present study is to examine the impact of ISES and NSES, as well as their interaction, on the risk of developing MCI over time in a sample of people over 70 years of age who have been followed-up for seven years.

\section{METHODS}

\section{Participants}

The Vallecas Project is an ongoing community-based longitudinal investigation for early detection of cognitive impairment and dementia (Olazarán et al., 2015). The study began in October 2011 and currently 6 complete waves of data collection have been performed over a follow-up period of 7 years. At baseline 1,180 community-dwelling individuals aged 70 and over were enrolled. All participants have undergone a detailed assessment protocol at every wave including medical history, neurological and neuropsychological examination, biochemical and genetic blood test, MRI scan, as well as information on lifestyle, well-being and socioeconomic circumstances. The complete assessment at every visit has been usually carried out within four hours with convenient breaks. Further details on the Vallecas Project are described in eMethods section (Supplement).

Ethical approval for the Vallecas Project was granted by the Research Ethics Committee of the Carlos III Institute of Health. Written informed consent was obtained from all the participants.

\section{Study variables}

\section{Socioeconomic indicators}

Different characteristics of SES were measured at baseline to ascertain two composite measures of SES:

1. ISES was estimated according to the following three variables:

- Educational attainment: (0) no formal qualifications; (1) primary education; (2) secondary education; and (3) higher education.

- Occupation: (0) non-qualified/homemaker; (1) manual work; (2) clerical work; (3) graduate/technician work; and (4) managerial positions.

- The highest level of education reached by parents: (0) no formal qualifications; (1) primary education; and (2) secondary or higher education.

2. NSES was based on six variables associated with neighborhoods that were retrieved from the Department of Statistics of Madrid City Council:

- Average annual net income: (0) up to $€ 24,999$; (1) $€ 25,000-€ 49,999$; and (2) $€ 50,000$ and over. 
- Percentage of people with no formal qualifications.

- Percentage of people with higher education.

- Percentage of white-collar workers.

- Unemployment rate.

- Housing price $(€ /$ square meter).

Each individual and neighborhood variable was firstly standardized to facilitate comparisons. Then, we calculated a z-score for every participant both in the ISES and in the NSES dimensions. Finally, the z-score distribution was split into quartiles where Q1 represented the worst-off and Q4 the best-off.

\section{Clinical diagnoses}

Every participant was independently diagnosed taking into account age, gender, functional information, and neuropsychological scores. Cognitive diagnoses were agreed between neurologists and neuropsychologists at consensus meetings. In all cases, cognitively healthy subjects had to obtain a score of 0 in the global Clinical Dementia Rating (CDR) (Hughes, Berg, \& Danziger, 1982). Criteria from the National Institute on AgingAlzheimer's Association (NIA-AA) were used to diagnose MCI (Albert et al., 2011).

\section{Covariates}

We considered age at conversion to MCI, gender, and ApoE genotyping as potential confounders for cognitive impairment. ApoE genotype was studied with total DNA isolated from peripheral blood following standard procedures. Genotyping of polymorphisms (rs429358 and rs7412) was performed by Real-Time PCR (Calero, Hortigüela, Bullido, \& Calero, 2009). ApoE was coded 1 for the $\varepsilon 4$-carriers, and 0 for non-carriers. Males and $\varepsilon 4$ carriers were used as reference groups.

\section{Statistical analyses}

We performed a preliminary analysis of the individual and neighborhood variables considered in this study. In all cases, associations between categorical variables were analyzed using Fisher or Pearson's $\chi^{2}$ test. The comparisons between cognitively unimpaired individuals and MCI were performed with the nonparametric Wilcoxon test due to the differences in sample sizes and to the non-adjustment to the parametric assumptions of most dependent variables. A complementary analysis of demographic, cognitive, clinical, anthropometric, and lifestyle variables at baseline to find out their relationships to SES is described in the Supplementary material.
Both ISES and NSES were treated as four-level independent variables defined by the quartile; upper quartile was always used as the reference group in the analyses. The association between ISES, NSES, and the last cognitive diagnosis registered in the follow-up for every participant was exploratory studied by means of contingency tables. Moreover, to analyze longitudinally the relationship between ISES, NSES, and conversion rate to MCI, two multivariate-adjusted Cox proportional hazard models were obtained. All the results were presented as hazard ratio (HR) with a $95 \%$ confidence interval (CI). Time to event was calculated as date of entry into the study to date of MCI diagnosis or the end of the study period. Age at MCI onset, gender, and ApoE genotype were introduced as covariates. The Schoenfeld residual test was used to test the proportional hazards assumption of the models. Finally, to study the interaction between the individual and the neighborhood dimensions of SES upon the MCI conversion, we created a new variable by crossing lower and upper quartiles of the ISES and the NSES. This resulted in a global SES (GSES) dimension with 4 categories ordered hypothetically from the highest $\left(\mathrm{Q}_{\mathrm{gses}} 1\right)$ to the lowest $\left(\mathrm{Q}_{\mathrm{gses}} 4\right)$ risk of MCI conversion. Then, a final third Cox proportional hazard model was obtained for GSES.

All analyses were conducted in $\mathrm{R}$ version 3.5.1. ( $\mathrm{R}$ Development Core Team, 2008). We used 2-sided significance tests for all analyses, with statistical significance set at $P$ Value $<0.05$.

\section{RESULTS}

The sample included in this study was composed of 1,180 individuals (median follow-up duration, 5 years; range, 1-7 years). The baseline diagnoses were 1,088 cognitively normal individuals, 83 MCI cases and 9 dementia patients. Table 1 shows the baseline characteristics of the sample.

A preliminary analysis only considering cognitively unimpaired and MCI subjects showed statistically significant differences in relation to all individual and neighborhood characteristics. A strong association was also found between ISES and NSES quartiles and both diagnostic groups whereby the upper quartiles showed a lower percentage of MCI cases than the lower quartiles (Table 1). A complementary examination of a large set of baseline variables of diverse nature was also conducted. The results showed a straight and linear trend always in favor of higher levels versus lower levels of SES in a large set of baseline variables of diverse nature (eTable 1 in the Supplement). Even controlling for the gender effect similar results were found what indicate that gender is not a confounder factor (eTable 2 and eTable 3 in the Supplement). 
Table 1. Baseline characteristics of the cohort by quartiles of individual and neighborhood socioeconomic status

\begin{tabular}{|c|c|c|c|c|c|}
\hline Characteristics, Mean (SD) & $\begin{array}{c}\text { Total } \\
(\mathrm{n}=1180)\end{array}$ & $\begin{array}{c}\text { Control } \\
(\mathrm{n}=1088)\end{array}$ & $\begin{array}{c}\mathrm{MCI} \\
(\mathrm{n}=83)\end{array}$ & $\begin{array}{c}\text { Dementia } \\
(n=9)\end{array}$ & $P$ Value $^{\mathrm{a}}$ \\
\hline \multicolumn{6}{|l|}{ Demographics } \\
\hline Age, y & $74.9(3.9)$ & 74.7 (3.9) & $77.2(3.7)$ & $79.9(3.0)$ & \multirow{3}{*}{$\begin{array}{c}<.001 \\
.288\end{array}$} \\
\hline Female, No. (\%) & $750(63.6)$ & $695(63.9)$ & $48(57.8)$ & $7(77.8)$ & \\
\hline \multicolumn{5}{|l|}{ Individual-level variables } & \\
\hline \multicolumn{6}{|l|}{ Education, No. (\%) } \\
\hline No formal qualifications & $240(20.4)$ & $202(18.6)$ & $35(42.2)$ & $3(33.3)$ & \multirow{4}{*}{$<.001$} \\
\hline Primary education & $360(30.6)$ & $325(29.9)$ & $29(34.9)$ & $6(66.7)$ & \\
\hline Secondary education & $279(23.7)$ & $268(24.7)$ & $11(13.3)$ & $0(0.0)$ & \\
\hline Higher education & $299(25.4)$ & $291(26.8)$ & $8(9.6)$ & $0(0.0)$ & \\
\hline \multicolumn{6}{|l|}{ Occupation, No. (\%) } \\
\hline Non-qualified/homemaker & $322(33.5)$ & $295(32.5)$ & $26(51.0)$ & $1(50.0)$ & \multirow{5}{*}{.006} \\
\hline Manual work & $222(23.1)$ & $206(22.7)$ & $15(29.4)$ & $1(50.0)$ & \\
\hline Clerical work & $149(15.5)$ & $143(15.7)$ & $6(11.8)$ & $0(0.0)$ & \\
\hline Graduate/technician work & $210(21.9)$ & $206(22.7)$ & $4(7.8)$ & $0(0.0)$ & \\
\hline Managerial positions & $58(6.0)$ & $58(6.4)$ & $0(0.0)$ & $0(0.0)$ & \\
\hline \multicolumn{6}{|l|}{ Parent's education, No. (\%) } \\
\hline No formal qualifications & $249(25.8)$ & $225(24.7)$ & $23(44.2)$ & $1(50.0)$ & \multirow{3}{*}{.004} \\
\hline Primary education & $515(53.4)$ & $490(53.8)$ & $24(46.2)$ & $1(50.0)$ & \\
\hline Secondary or Higher & $200(20.7)$ & $195(21.4)$ & $5(9.2)$ & $0(0.0)$ & \\
\hline \multicolumn{6}{|l|}{ Neighborhood-level variables } \\
\hline Average annual net income, $€$ & $35051(13854)$ & 35385 (14096) & $31113(7845)$ & $31020(7845)$ & .004 \\
\hline Proportion of no qualifications & $20.3(9.7)$ & $20.0(9.7)$ & $23.6(8.8)$ & $22.9(8.2)$ & .001 \\
\hline Proportion of higher education & $29.8(18.1)$ & $30.3(18.1)$ & $23.8(15.9)$ & $24.9(15.3)$ & .001 \\
\hline Proportion of white-collar workers & $45.7(15.9)$ & $46.2(16.0)$ & $40.4(13.0)$ & $39.2(15.1)$ & .002 \\
\hline Unemployment rate & $9.0(2.6)$ & $9.0(2.6)$ & $9.9(2.4)$ & $9.5(2.1)$ & .001 \\
\hline Housing price, $€ / \mathrm{m}^{2}$ & 2374 (1103) & $2403(1115)$ & 2044 (919) & 2046 (736) & .003 \\
\hline \multicolumn{6}{|l|}{ ISES, No. (\%) } \\
\hline Q1 & $292(24.8)$ & $251(23.1)$ & $37(44.6)$ & $4(44.4)$ & \multirow{4}{*}{$<.001$} \\
\hline Q4 & $290(24.5)$ & $258(23.7)$ & $27(32.5)$ & $5(55.6)$ & \\
\hline Q3 & 305 (25.9) & $293(27.0)$ & $12(14.5)$ & $0(0.0)$ & \\
\hline Q4 & $293(24.8)$ & $286(26.2)$ & $7(8.4)$ & $0(0.0)$ & \\
\hline \multicolumn{6}{|l|}{ NSES, No. (\%) } \\
\hline Q1 & $296(25.1)$ & $257(23.6)$ & $36(43.4)$ & $3(33.3)$ & \multirow{4}{*}{$<.001$} \\
\hline Q4 & $298(25.3)$ & $277(25.5)$ & $19(22.9)$ & $2(22.2)$ & \\
\hline Q3 & $292(24.7)$ & $271(24.9)$ & $17(20.5)$ & $4(44.4)$ & \\
\hline Q4 & 294 (24.9) & $283(26.0)$ & $11(13.3)$ & $0(0.0)$ & \\
\hline
\end{tabular}

Abbreviations: ISES, individual socioeconomic status; NSES, neighborhood socioeconomic status.

${ }^{\text {a }}$ Since the small sample size of the dementia group, variables were compared only between Control and Mild Cognitive Impairment. Fisher and Pearson's $\chi^{2}$ test for categorical and non-parametric Wilcoxon for ordinal variables tests were used. ISES an NSES quartiles follow an ordinal distribution so that the upper quartile (Q4) corresponded to the best off, while the lower one (Q1) were referred to the worst off. 
Figure 1 shows the percentage of individuals who were diagnosed as cognitively unimpaired throughout the visits at the Vallecas Project by ISES (bars in blue) and NSES (bars in red). As expected the percentage of cognitively intact subjects was decreasing over the follow-up, thus increasing the number of MCI patients: a total of 199 subjects with MCI (16.9\%) were

a) Cognitively unimpaired subjects by Individual Socioeconomic Status (ISES)

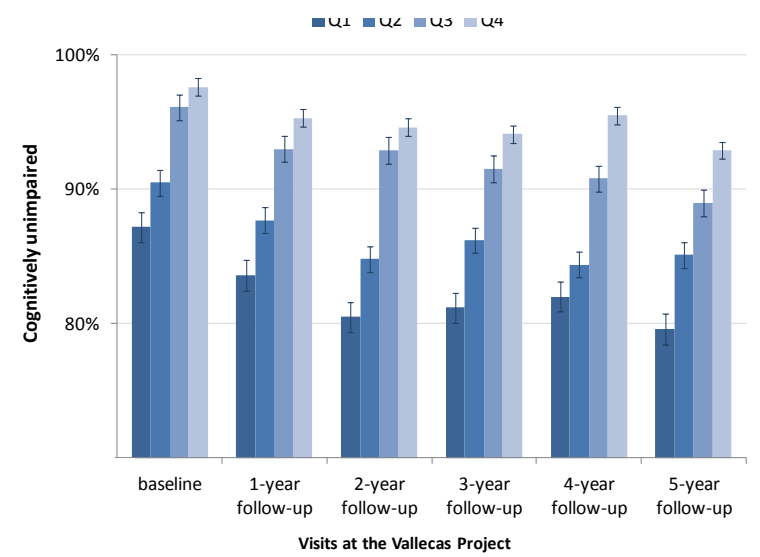

identified. Interestingly, the age at MCI onset for lower quartiles (Q1-Q2) was earlier than for upper ones (Q3Q4) both for ISES (77.1 vs 79.8 years old) and for NSES (76.8 vs 80.5 years old). Moreover, the distribution of the MCI prevalence with age is different for ISES and NSES as shown in Figure 2.

b) Cognitively unimpaired subjects by Neighborhood Socioeconomic Status (NSES)

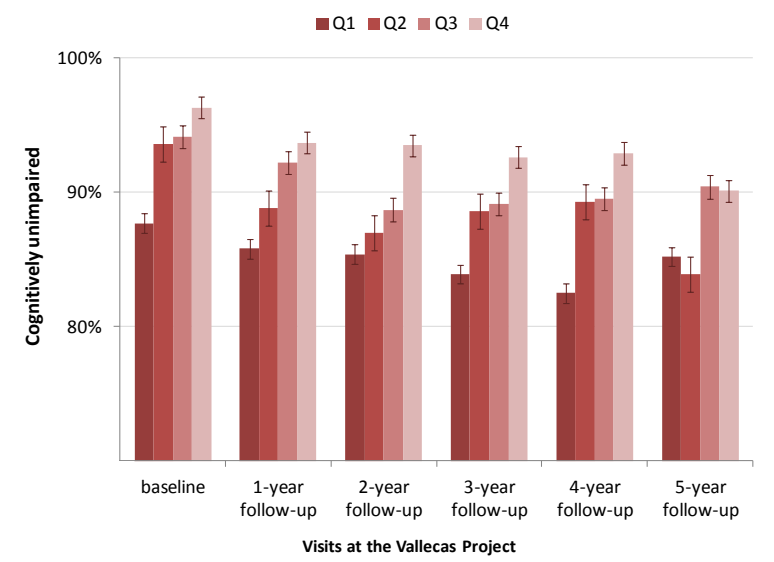

Figure 1. Individuals diagnosed as cognitively unimpaired throughout the visits at the Vallecas Project

The association between socioeconomic status and the last cognitive diagnosis registered for each participant was analyzed. We then found significant statistical differences for ISES $\left(\chi^{2}, 20.12 ; P=.003\right)$, with a greater percentage of MCI cases in lower versus upper quartiles especially at the ages of 75-85. However, even though a similar pattern of results was

a) Prevalence of Mild Cognitive Impairment by Individual Socioeconomic Status (ISES)

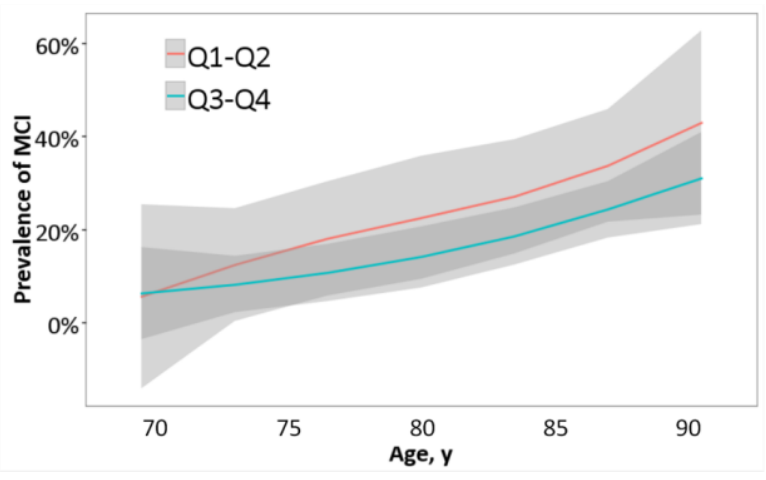

observed for NSES until the age of 80 , no clear association was obtained with clinical diagnoses $\left(\chi^{2}\right.$, $7.08 ; P=.314)$. As showed in Figure $2 b$, this outcome was mainly due to an unexpected decrease in the prevalence of MCI in the lower NSES quartiles in comparison to upper ones in which prevalence continued to rise.

b) Prevalence of Mild Cognitive Impairment by Neighborhood Socioeconomic Status (NSES)

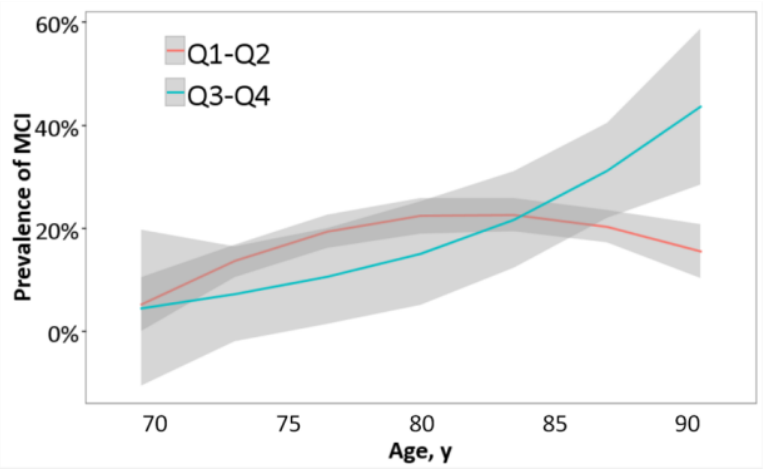

Figure 2. Mild Cognitive Impairment prevalence throughout ageing

Abbreviations: MCI, Mild Cognitive Impairment; Q, quartile.

To better illustrate the rate of MCI progression according to age, the initial quartiles were collapsed in two categories representing lower (Q1-Q2) and upper (Q3-Q4) quartiles. As expected, there is an overall increase of MCI prevalence with age for both ISES (2a) and NSES (2b); lower quartiles show a major percentage of MCI diagnoses than upper quartiles, especially for ISES and between $70-80$ years. However, some differences can be appreciated when inspecting both figures. While lower and upper quartiles in ISES follow the same trend with respect to MCI, in NSES there is a decrease in the percentage of individuals with MCI from the age of 85 onwards. This phenomenon is associated with the attrition of the cohort which is more marked in lower quartiles probably due to several factors intrinsically associated to NSES such as lower expectancy of life, major rate of disability, or worse general health status. 
Finally, the unadjusted Cox proportional hazard models longitudinally confirmed the results that lower quartiles had an increased risk of progression to MCI compared to upper ones. Specifically, the analysis of the interaction of individual and neighborhood dimensions showed that GSES Q1 and Q2 had about a $60-67 \%$ increased risk of MCI progression compared to GSES Q4. Kaplan-Meier plots showed clear differences in risk by Q1 and Q2 after 7 years of follow-up (Figure
3). On the other hand, adjusted Cox regression models were also conducted to control the influence of age at MCI onset, gender, and ApoE genotype upon GSES and its association with conversion to MCI. As shown in Table 2, compared to GSES Q4 the multivariate adjusted HRs were 1.83 (95\% CI, 1.04-3.21) for GSES Q1 and 1.74 (95\% CI, 1.06-2.86) for GSES Q2. GSES Q3 did not differ from Q4.

Table 2. Cox proportional hazard regression models of conversion rate to MCI

\begin{tabular}{|c|c|c|c|c|c|c|}
\hline & \multicolumn{2}{|c|}{ Model 1 $^{\mathrm{a}}$} & \multicolumn{2}{|c|}{ Model 2 ${ }^{\mathrm{b}}$} & \multicolumn{2}{|c|}{ Model 3 ${ }^{\mathrm{c}}$} \\
\hline & HR (95\% CI) & $P$ Value & HR (95\% CI) & $P$ Value & HR (95\% CI) & $P$ Value \\
\hline $\mathbf{Q 4}^{\mathrm{d}}$ & 1 [Reference] & - & 1 [Reference] & - & 1 [Reference] & - \\
\hline Q3 & $1.62(0.96-2.73)$ & .071 & $1.05(0.62-1.77)$ & .860 & $1.26(0.30-5.39)$ & .755 \\
\hline Q2 & $1.71(0.95-3.07)$ & .076 & $1.15(0.69-1.92)$ & .587 & $1.74(1.06-2.86)$ & .030 \\
\hline Q1 & $1.95(1.12-3.40)$ & .018 & $1.07(0.62-1.84)$ & .803 & $1.83(1.04-3.21)$ & .036 \\
\hline
\end{tabular}

Abbreviations: CI, Confidence Interval; HR, Hazard Ratio; Q, quartile.

${ }^{a}$ Model 1: adjusted for age at MCI onset, gender, ApoE, and ISES

${ }^{\mathrm{b}}$ Model 2: adjusted for age at MCI onset, gender, ApoE, and NSES

${ }^{\mathrm{c}}$ Model 3: adjusted for age at MCI onset, gender, ApoE, and GSES.

${ }^{\mathrm{d}}$ Quartiles follow an ordinal distribution so that the upper quartile (Q4) corresponded to the best off, while the lower one (Q1) were referred to the worst off.

\section{DISCUSSION}

Our study aimed to examine the relative impact of individual and neighborhood dimensions of SES, as well as their interaction, on the risk of developing MCI in a sample of older adults that were followed-up for seven years. Overall, our results support the idea that there is a definite relationship between SES and risk of developing MCI in elderly people.

In our sample a moderate-high overlapping between ISES and NSES was found. This overlapping seems to be mediated by individual factors such as educational attainment. What can be inferred from this finding is that there was very little social promotion in our cohort born between 1925 and 1944. This segment of population suffered directly both the effects of the Spanish civil war (1936-1939) and the economic consequences of the postwar period. If a person was born in a disadvantaged environment then that person was more likely to remain in a deprived environment because of the scarcity of opportunities in relation to education as an element in reducing social inequalities. We hypothesize that this phenomenon is gradually being alleviated in next generations thanks to the improvement of the socioeconomic context and the universal access to education. The normalization of international relationships of Spain with the introduction of the parliamentary democracy after Franco's dictatorial regime has played an important role in shortening social distances in our country.
Our results show an increase in the prevalence of the MCI as a function of age for ISES and NSES which is consistent with other similar studies (Kim et al., 2017; Wee et al., 2012). For both SES dimensions, subjects in lower quartiles showed a higher rate of MCI than those in upper ones, especially between 70 and 80 of age. However, as depicted in Figure 2, from 80 onwards there was a different trend that affected lower quartiles of both SES dimensions: while in ISES the prevalence of MCI increased, in NSES there was a decrease. This outcome could be associated with the attrition to our study which mainly affects to persons that lived in deprived areas. The reasons that can explain such high attrition include factors intrinsically associated with NSES such as greater morbidity and earlier mortality (Kopp, Skrabski, Réthelyi, Kawachi, \& Adler, 2004), major rate of physical disability and worse general health status (Veenstra, 2000), and greater stress and worse psychological well-being (Everson-Rose et al., 2011; Präg, Mills, \& Wittek, 2016). Ultimately, Figure 2 reflects the importance of considering the conjunction of ISES and NSES dimensions to better explain the dynamics in the occurrence of the MCI.

The impact of GSES on the conversion rate to MCI during 7-year follow-up showed that the risk of developing cognitive impairment was almost double for lower quartiles than for upper ones. According to our results, elderly people with low-GSES have $60-67 \%$ increased risk of developing MCI than those with highGSES. Thus, low-GSES may be considered a risk factor for MCI. These data are consistent with previous findings in the literature (Goldbourt, Schnaider-Beeri, \& 
Davidson, 2007; Kim et al., 2017) and could have several explanations. First, high-SES is usually related to wealth what is directly associated with the possibility of consuming products, goods and services that provide positive effects upon health and cognition (Diez Roux \& Mair, 2010; Rosso et al., 2016). Second, high-SES is also related to cognitive enriched environments which favor the growth of social networks, emotional support, major sense of social effectiveness, and better general health condition (Berkman, Glass, Brissette, \& Seeman, 2000; Kim \& Park, 2015). Third, NSES is able to influence individual's health through a series of environmental variables that include exposures to crime or pollution, proximity to services such as hospitals or parks, etc. (Sharkey \& Faber, 2014). Fourth, low-NSES have often more chronic stressors and fewer resources compared to high-NSES, and this might lead to restricted opportunities for social and cognitive stimulation as well as less access to good health services (Barnes, Mendes de Leon, Wilson, Bienias, \& Evans, 2004; Ertel, Glymour, \& Berkman, 2008). Fifth, as a result of difficulty making ends meet for individuals with low-SES, they tend to be more depressed and stressed which may lead to faster ageing (Kondo, 2012). Finally, high-SES might not only improve life conditions but also facilitate the ability and motivation to participate in activities that improve the well-being which indirectly may help to prevent cognitive disorders (Sattler, Toro, Schönknecht, \& Schröder, 2012).

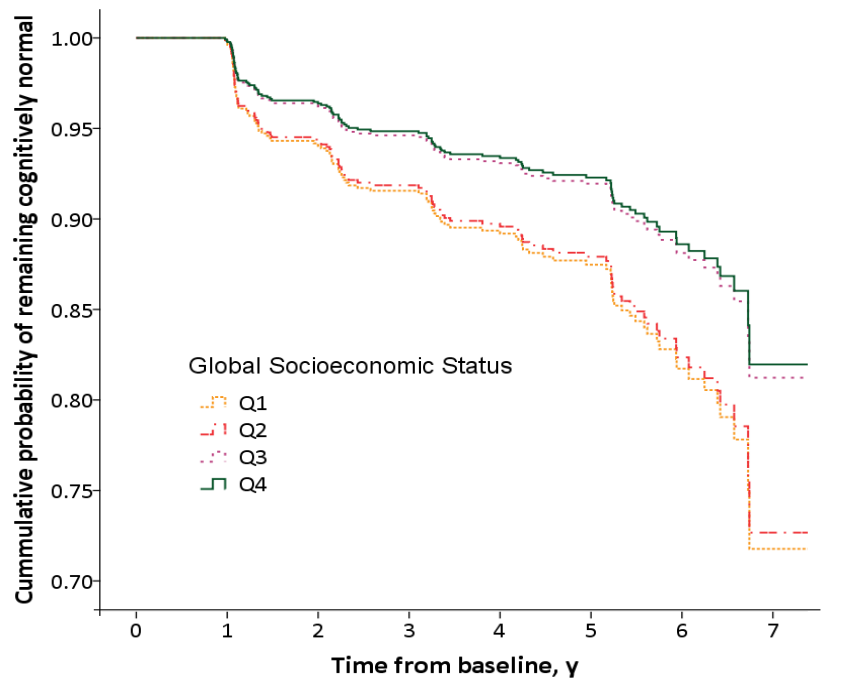

Figure 3. Kaplan-Meier survival curves for rates of Mild Cognitive Impairment by Global Socioeconomic Status quartiles

Survival curves based on Cox regression analysis comparing cumulative Mild Cognitive Impairment (MCI) incidence in subjects cognitively normal at baseline by each Global Socioeconomic Status (GSES) quartile. The figure is derived from a model that is adjusted for age of diagnostic, sex and APOE genotype. Duration of follow-up is truncated at 7 years. Q1 and Q2 show the highest risk of conversion to $\mathrm{MCI}$ compared with $\mathrm{Q} 4$.
In terms of the cognitive reserve hypothesis (Stern, 2002, 2012), and based on our results, we propose that the two SES dimensions considered in this study play complementary roles in brain and cognitive functioning. On the one hand, ISES which was defined as a combination of three factors -educational attainment, occupation and parents' the highest level of educationappears to be associated with the concept of cognitive reserve. High-ISES would be related to a greater acquisition of knowledge and effective cognitive strategies from childhood to adulthood. In addition, high-SES individuals tend to have healthy behaviors which include read and practice more cultural and leisure activities which also helps maintain cognitive reserve capacity (Pampel, Krueger, \& Denney, 2010). This would allow explaining why MCI is more prevalent for low-ISES than high-ISES through the lifespan as cognitive reserve is able to compensate the neuropathological damages related to cognitive ageing. On the other hand, NSES, a composite score based on characteristics of the neighborhood in which a person lives, seems to impact further on brain reserve. The best living conditions (e.g. diet, cognitive stimulation, access to health services, etc.) that are supposedly associated with high-NSES, especially in the early life, would allow for greater neurocognitive and brain development (Hackman, Farah, \& Meaney, 2010). In any event, early experiences like amount and quality of education could override the influences of the neighborhood context, being more important in predicting later cognitive performance (Glymour \& Manly, 2008).

The findings of this study have two important implications. First, the dynamics and prevalence of MCI through ageing is conditioned by the SES of individuals. This has implications for health care professionals as far as they should take into account both the individual characteristics and the socioeconomic context to better understand MCI. Second, it is crucial to go beyond the classical perspective on individual preventive strategies for dementia based on lifestyle modifications (e.g. diet, physical activity or cognitive training). We consider policies that targeting the reduction of social inequalities also offer a means of promoting healthy ageing in society. For example, policies aimed at reducing disparities in wealth or favoring access to educational or health resources for the most disadvantaged people. The understanding of how SES relates to cognitive function could help policy-makers to design strategies for prevention and intervention for older adults (Hackman et al., 2010; Meyer et al., 2018).

\section{Strengths}

To our knowledge, this is the first longitudinal study that examines separately the influence of the two dimensions of SES on the prevalence of MCI, a 
prodromal stage that is considered to increase the probability of suffering latter dementia (Jack et al., 2018; Petersen, 2004). Through a 7-year follow-up of a well-characterized cohort of older adults that has been tracked annually, we have been able to demonstrate the association of ISES and NSES on cognitive diagnoses. Moreover, we have benefited from the availability of official and accurate statistical data about neighborhoods made available to the general public by the Department of Statistics of Madrid City Council.

\section{Limitations}

There is a lack of longitudinal information on individuals who discontinued the study. Therefore, we cannot be certain of the mortality rate of the entire cohort and all we can do is speculate on the reason for the loss of subjects in NSES Q1 and Q2 from approximately 80 years of age. Moreover, since no specific information on biomarkers is available in our study, we cannot determine the etiology of each MCI case. It ought to be noted that diagnosis of MCI is multifactorial; a set of candidate causes, both reversible and non-reversible, could play a role in the diagnosis (Petersen et al., 2014).

\section{Conclusions}

In a well-characterized Spanish cohort of older adults, the risk of MCI was associated with the two dimensions of SES, and specifically the effect of ISES was consistently higher. However, since ISES and NSES have different effects mediated by age on cognitive impairment, the interplay of both SES dimensions must be considered. Public health strategies should focus not only on promoting the classical individual preventive measures (e.g. through lifestyle modification), but also on reducing social inequalities (e.g. by favoring access to educational and health resources for the most disadvantaged people) as a means to foster healthy ageing and reduce dementia burden.

\section{Acknowledgments}

We wish to thank the research participants and the staff of the CIEN Foundation.

\section{Author contributions}

Drs Fernández-Blázquez, Del Ser, and Gómez-Ramírez had full access to all the data in the study and take responsibility for the integrity of the data and the accuracy of the data analysis.

Study concept and design: Fernández-Blázquez, ÁvilaVillanueva, Del Ser, Gómez-Ramírez.

Acquisition, analysis, or interpretation of data: All authors.

Drafting of the manuscript: Fernández-Blázquez, Noriega-Ruiz.
Critical revision of the manuscript for important intellectual content: All authors.

Statistical analysis: Fernández-Blázquez

Study supervision: Del Ser, Gómez-Ramírez.

\section{Conflict of interest disclosures}

The authors report no conflicts of interest relevant to the manuscript.

\section{Funding/support}

The Queen Sofia Foundation (http://www.fundacionreinasofia.es/ES/Paginas/home.as px) and the Carlos III Institute of Health (http://www.isciii.es/) supported and funded the clinical and research activity of the Alzheimer's Disease Research Unit in Madrid (Spain), where all the authors are currently working in the Vallecas Project (registered at the JPND Global Cohort Portal). The reported study has not had a specific grant; it was performed as part of the research activity of the authors.

\section{Role of the funder/sponsor}

The funders had no role in design and conduct of the study; collection, management, statistical analysis, and interpretation of the data; preparation, drafting, review, or approval of the manuscript; and decision to submit the manuscript for publication.

\section{REFERENCES}

Åberg Yngwe, M., Kondo, N., Hägg, S., \& Kawachi, I. (2012). Relative deprivation and mortality--a longitudinal study in a Swedish population of 4.7 million, 1990-2006. BMC Public Health, 12, 664. https://doi.org/10.1186/1471-2458-12-664

Adler, N. E., \& Stewart, J. (2010). Health disparities across the lifespan: meaning, methods, and mechanisms. Annals of the New York Academy of Sciences, 1186(1), 5-23. https://doi.org/10.1111/j.1749-6632.2009.05337.x

Albert, M. S., DeKosky, S. T., Dickson, D., Dubois, B., Feldman, H. H., Fox, N. C., ... Phelps, C. H. (2011). The diagnosis of mild cognitive impairment due to Alzheimer's disease: Recommendations from the National Institute on Aging and Alzheimer's Association workgroup. Alzheimer's \& Dementia: The Journal of the Alzheimer's Association, 7(3), 270-279. https://doi.org/10.1016/j.jalz.2011.03.008

Barnes, L. L., Mendes de Leon, C. F., Wilson, R. S., Bienias, J. L., \& Evans, D. A. (2004). Social resources and cognitive decline in a population of older African Americans and whites. Neurology, 63(12), 2322-2326. https://doi.org/10.1212/01.WNL.0000147473.040 43.B3

Berkman, L. F., Glass, T., Brissette, I., \& Seeman, T. E. (2000). From social integration to health: 
Durkheim in the new millennium. Social Science \& Medicine (1982), 51(6), 843-857. Retrieved from

http://www.ncbi.nlm.nih.gov/pubmed/10972429

Besser, L. M., McDonald, N. C., Song, Y., Kukull, W. A., \& Rodriguez, D. A. (2017). Neighborhood Environment and Cognition in Older Adults: A Systematic Review. American Journal of Preventive Medicine, 53(2), 241-251. https://doi.org/10.1016/j.amepre.2017.02.013

Braveman, P. A., Cubbin, C., Egerter, S., Chideya, S., Marchi, K. S., Metzler, M., \& Posner, S. (2005). Socioeconomic Status in Health Research. JAMA, 294(22), 2879. https://doi.org/10.1001/jama.294.22.2879

Cadar, D., Lassale, C., Davies, H., Llewellyn, D. J., Batty, G. D., \& Steptoe, A. (2018). Individual and Area-Based Socioeconomic Factors Associated With Dementia Incidence in England. JAMA Psychiatry, 75(7),

723. https://doi.org/10.1001/jamapsychiatry.2018.1012

Calero, O., Hortigüela, R., Bullido, M. J., \& Calero, M. (2009). Apolipoprotein E genotyping method by Real Time PCR, a fast and cost-effective alternative to the TaqMan ${ }^{\circledR}$ and FRET assays. Journal of Neuroscience Methods, 183(2), 238240.

https://doi.org/10.1016/j.jneumeth.2009.06.033

Chan, M. Y., Na, J., Agres, P. F., Savalia, N. K., Park, D. C., \& Wig, G. S. (2018). Socioeconomic status moderates age-related differences in the brain's functional network organization and anatomy across the adult lifespan. Proceedings of the National Academy of Sciences of the United States of America, 115(22), E5144-E5153. https://doi.org/10.1073/pnas.1714021115

Diez Roux, A. V., \& Mair, C. (2010). Neighborhoods and health. Annals of the New York Academy of Sciences, 1186(1), 125-145. https://doi.org/10.1111/j.1749-6632.2009.05333.x

Eibner, C., \& Evans, W. N. (2005). Relative Deprivation, Poor Health Habits, and Mortality. The Journal of Human Resources, 40(3), 591-620. https://doi.org/10.2307/4129553

Ertel, K. A., Glymour, M. M., \& Berkman, L. F. (2008). Effects of social integration on preserving memory function in a nationally representative US elderly population. American Journal of Public Health, 98(7),

1215-1220.

https://doi.org/10.2105/AJPH.2007.113654

Everson-Rose, S. A., Skarupski, K. A., Barnes, L. L., Beck, T., Evans, D. A., \& Mendes de Leon, C. F. (2011). Neighborhood socioeconomic conditions are associated with psychosocial functioning in older black and white adults. Health \& Place, 17(3),

793-800.

https://doi.org/10.1016/j.healthplace.2011.02.007
Farah, M. J. (2017). The Neuroscience of Socioeconomic Status: Correlates, Causes, and Consequences. Neuron, 96(1), 56-71. https://doi.org/10.1016/j.neuron.2017.08.034

Glymour, M. M., \& Manly, J. J. (2008). Lifecourse social conditions and racial and ethnic patterns of cognitive aging. Neuropsychology Review, 18(3), 223-254. https://doi.org/10.1007/s11065-0089064-z

Goldbourt, U., Schnaider-Beeri, M., \& Davidson, M. (2007). Socioeconomic status in relationship to death of vascular disease and late-life dementia. Journal of the Neurological Sciences, 257(1-2), 177-181. https://doi.org/10.1016/j.jns.2007.01.021

Hackman, D. A., Farah, M. J., \& Meaney, M. J. (2010). Socioeconomic status and the brain: mechanistic insights from human and animal research. Nature Reviews. Neuroscience, 11(9), 651-659. https://doi.org/10.1038/nrn2897

Hughes, C. P., Berg, L., \& Danziger, W. L. (1982). A new clinical scale for the staging of dementia. British Journal of Psychiatry, 140(6), 566-572. https://doi.org/10.1192/bjp.140.6.566

Jack, C. R., Bennett, D. A., Blennow, K., Carrillo, M. C., Dunn, B., Haeberlein, S. B., ... Contributors, R. (2018). NIA-AA Research Framework: Toward a biological definition of Alzheimer's disease. Alzheimer's \& Dementia: The Journal of the Alzheimer's Association, 14(4), 535-562. https://doi.org/10.1016/j.jalz.2018.02.018

Kessler, R. C., Berglund, P., Demler, O., Jin, R., Merikangas, K. R., \& Walters, E. E. (2005). Lifetime Prevalence and Age-of-Onset Distributions of DSM-IV Disorders in the National Comorbidity Survey Replication. Archives of General Psychiatry, 62(6), 593. https://doi.org/10.1001/archpsyc.62.6.593

Kim, G. H., Lee, H. A., Park, H., Lee, D. Y., Jo, I., Choi, S. H., ... Jeong, J. H. (2017). Effect of Individual and District-level Socioeconomic Disparities on Cognitive Decline in Communitydwelling Elderly in Seoul. Journal of Korean Medical Science, 32(9), 1508. https://doi.org/10.3346/jkms.2017.32.9.1508

Kim, J.-H., \& Park, E.-C. (2015). Impact of socioeconomic status and subjective social class on overall and health-related quality of life. $B M C$ Public Health, 15(1), 783. https://doi.org/10.1186/s12889-015-2014-9

Kondo, N. (2012). Socioeconomic disparities and health: impacts and pathways. Journal of Epidemiology, 22(1), 2-6. Retrieved from http://www.ncbi.nlm.nih.gov/pubmed/22156290

Kopp, M., Skrabski, A., Réthelyi, J., Kawachi, I., \& Adler, N. E. (2004). Self-rated health, subjective social status, and middle-aged mortality in a changing society. Behavioral Medicine 
(Washington, $\quad$ D.C.), $\quad 30(2), \quad 65-70$. https://doi.org/10.3200/BMED.30.2.65-72

Krieger, N., Williams, D. R., \& Moss, N. E. (1997). Measuring Social Class in US Public Health Research: Concepts, Methodologies, and Guidelines. Annual Review of Public Health, 18(1), 341-378. https://doi.org/10.1146/annurev.publhealth.18.1.34 1

Lorant, V., Deliège, D., Eaton, W., Robert, A., Philippot, P., \& Ansseau, M. (2003). Socioeconomic Inequalities in Depression: A Meta-Analysis. American Journal of Epidemiology, $\quad$ 157(2), 98-112. https://doi.org/10.1093/aje/kwf182

Lyu, J., \& Burr, J. A. (2016). Socioeconomic Status Across the Life Course and Cognitive Function Among Older Adults. Journal of Aging and Health, 28(1), 40-67. https://doi.org/10.1177/0898264315585504

Marden, J. R., Tchetgen Tchetgen, E. J., Kawachi, I., \& Glymour, M. M. (2017). Contribution of Socioeconomic Status at 3 Life-Course Periods to Late-Life Memory Function and Decline: Early and Late Predictors of Dementia Risk. American Journal of Epidemiology, 186(7), 805-814. https://doi.org/10.1093/aje/kwx155

Mayén, A.-L., Marques-Vidal, P., Paccaud, F., Bovet, P., \& Stringhini, S. (2014). Socioeconomic determinants of dietary patterns in low- and middle-income countries: a systematic review. The American Journal of Clinical Nutrition, 100(6), 1520-1531.

https://doi.org/10.3945/ajcn.114.089029

Meyer, O. L., Mungas, D., King, J., Hinton, L., Farias, S., Reed, B., ... Beckett, L. (2018). Neighborhood Socioeconomic Status and Cognitive Trajectories in a Diverse Longitudinal Cohort. Clinical Gerontologist, $\quad 41(1), \quad 82-93$. https://doi.org/10.1080/07317115.2017.1282911

Nakahori, N., Sekine, M., Yamada, M., Tatsuse, T., Kido, H., \& Suzuki, M. (2018). A pathway from low socioeconomic status to dementia in Japan: results from the Toyama dementia survey. $B M C$ Geriatrics, 18(1), 102. https://doi.org/10.1186/s12877-018-0791-6

Olazarán, J., Valentí, M., Frades, B., Zea-Sevilla, M. A., Ávila-Villanueva, M., Fernández-Blázquez, M. Á., ... Martínez-Martín, P. (2015). The Vallecas Project A Cohort to Identify Early Markers and Mechanisms of Alzheimer's Disease. Frontiers in Aging Neuroscience, 7, 181. https://doi.org/10.3389/fnagi.2015.00181

Pampel, F. C., Krueger, P. M., \& Denney, J. T. (2010). Socioeconomic Disparities in Health Behaviors. Annual Review of Sociology, 36, 349-370. https://doi.org/10.1146/annurev.soc.012809.10252
9

Petersen, R. C. (2004). Mild cognitive impairment as a diagnostic entity. Journal of Internal Medicine, 256(3), 183-194. https://doi.org/10.1111/j.13652796.2004.01388.x

Petersen, R. C., Caracciolo, B., Brayne, C., Gauthier, S., Jelic, V., \& Fratiglioni, L. (2014). Mild cognitive impairment: a concept in evolution. Journal of Internal Medicine, 275(3), 214-228. https://doi.org/10.1111/joim. 12190

Präg, P., Mills, M. C., \& Wittek, R. (2016). Subjective socioeconomic status and health in cross-national comparison. Social Science \& Medicine, 149, 8492.

https://doi.org/10.1016/j.socscimed.2015.11.044

$\mathrm{R}$ Development Core Team. (2008). R: A Language and Environment for Statistical Computing. Vienna Austria R Foundation for Statistical Computing (Vol. 1). Vienna: R Foundation for Statistical Computing. Retrieved from http://www.rproject.org

Rosso, A. L., Flatt, J. D., Carlson, M. C., Lovasi, G. S., Rosano, C., Brown, A. F., ... Gianaros, P. J. (2016). Neighborhood Socioeconomic Status and Cognitive Function in Late Life. American Journal of Epidemiology, 183(12), 1088-1097. https://doi.org/10.1093/aje/kwv337

Russ, T. C., Stamatakis, E., Hamer, M., Starr, J. M., Kivimäki, M., \& Batty, G. D. (2013). Socioeconomic status as a risk factor for dementia death: individual participant meta-analysis of 86 508 men and women from the UK. The British Journal of Psychiatry: The Journal of Mental Science, 203(1), 10-17. https://doi.org/10.1192/bjp.bp.112.119479

Sattler, C., Toro, P., Schönknecht, P., \& Schröder, J. (2012). Cognitive activity, education and socioeconomic status as preventive factors for mild cognitive impairment and Alzheimer's disease. Psychiatry Research, 196(1), 90-95. https://doi.org/10.1016/j.psychres.2011.11.012

Sharkey, P., \& Faber, J. W. (2014). Where, When, Why, and For Whom Do Residential Contexts Matter? Moving Away from the Dichotomous Understanding of Neighborhood Effects. Annual Review of Sociology, 40(1), 559-579. https://doi.org/10.1146/annurev-soc-071913043350

Stern, Y. (2002). What is cognitive reserve? Theory and research application of the reserve concept. Journal of the International Neuropsychological Society, $8(3), \quad 448-460$. https://doi.org/10.1017/S1355617702813248

Stern, Y. (2012). Cognitive reserve in ageing and Alzheimer's disease. The Lancet Neurology, 11(11), 1006-1012. https://doi.org/10.1016/S1474-4422(12)70191-6 
van de Vorst, I. E., Koek, H. L., Stein, C. E., Bots, M. L., \& Vaartjes, I. (2016). Socioeconomic Disparities and Mortality After a Diagnosis of Dementia: Results From a Nationwide Registry Linkage Study. American Journal of Epidemiology, 184(3), 219-226. https://doi.org/10.1093/aje/kwv319

Veenstra, G. (2000). Social capital, SES and health: an individual-level analysis. Social Science \& Medicine (1982), 50(5), 619-629. Retrieved from http://www.ncbi.nlm.nih.gov/pubmed/10658843

Waldstein, S. R., Dore, G. A., Davatzikos, C., Katzel, L. I., Gullapalli, R., Seliger, S. L., ... Zonderman, A. B. (2017). Differential Associations of Socioeconomic Status With Global Brain Volumes and White Matter Lesions in African American and White Adults. Psychosomatic Medicine,
$79(3)$,

$327-335$ https://doi.org/10.1097/PSY.0000000000000408

Wee, L. E., Yeo, W. X., Yang, G. R., Hannan, N., Lim, K., Chua, C., ... Shen, H. M. (2012). Individual and Area Level Socioeconomic Status and Its Association with Cognitive Function and Cognitive Impairment (Low MMSE) among Community-Dwelling Elderly in Singapore. Dementia and Geriatric Cognitive Disorders Extra, 2(1), 529-542. https://doi.org/10.1159/000345036

Weng, P.-H., Chen, J.-H., Chiou, J.-M., Tu, Y.-K., Chen, T.-F., Chiu, M.-J., ... Chen, Y.-C. (2018). The effect of lifestyle on late-life cognitive change under different socioeconomic status. PloS One, 13(6), e0197676. https://doi.org/10.1371/journal.pone.0197676 


\section{SUPPLEMENTARY ONLINE CONTENT}

\section{eMethods}

The Vallecas Project for early detection of AD is the most ambitious community-based study for healthy aging in Spain.(Olazarán et al., 2015) The project is an ongoing single-center, observational, longitudinal cohort study that is carried out at the Queen Sofia Foundation Alzheimer Center by a multidisciplinary team of researchers from the CIEN Foundation. The main objective of the Vallecas Project is to identify, through monitoring progression of the cohort, the best combination of features, clinical and others that are informative about developing cognitive impairment in the future. The participants were recruited between 2011 and 2013 in Madrid (Spain) and were home-dwelling volunteers, aged 70 to 85 years, without relevant psychiatric, neurologic or systemic disorders. After signing informed consent, they undertake a yearly systematic clinical assessment including medical history, neurological and neuropsychological exam, blood collection and brain MRI. The study was approved by the Ethics Committee of the Carlos III Institute of Health.

For the purposes of our study we have analyzed the association of ISES and NSES with the following set of variables collected in the Vallecas Project at baseline:

1. Demographics:

\subsection{Age, years.}

1.2. Education: No. (\%) of people with higher education.

1.3. Occupation: No. (\%) of white-collar workers.

1.4. Gender: No. (\%) of females.

1.5. ApoE: No. (\%) of $\varepsilon 4$-carriers.

2. Clinical:

- Hypertension: No. (\%) of people with hypertension.

- Cholesterol: No. (\%) of people with high levels of cholesterol.

- Diabetes: No. (\%) of people with diabetes.

- Stroke: No. (\%) of people with stroke with no apparent cognitive or motor impairment.

- Smoking: No. $(\%)$ of people smokers or ex-smokers.

- Depression: No. (\%) of people with depressive symptoms.

- Auditory deficit: No. (\%) of people with corrected or uncorrected hearing impairment.

- Visual deficit: No. (\%) of people with corrected or uncorrected visual impairment.

3. Cognitive status:

- $\quad$ Mini Mental Status Examination (MMSE): total score (range, 0-30); high scores reflect better cognitive performance.

- $\quad$ Free and Cued Selective Reminding Test (FCSRT): number of words correctly recalled both immediately (range, 0-48) and delayed (range, 0-16); high scores reflect better verbal memory performance.

- Semantic fluency: number of animals mentioned in a minute (no range); high scores reflect better language performance.

- $\quad$ Digit-Symbol: total number of correctly transposed symbols in one minute (no range); high scores reflect faster processing speed and better attentional performance. 
- Functional Activities Questionnaire (FAQ): total score (range, 0-33); high scores reflect a higher level of dependence on managing activities of daily living.

- Clinical Dementia Rating (CDR): sum of boxes score (range, 0-18); high scores reflect greater severity of cognitive impairment.

4. Neuroimaging:

- Gray matter volume, $\mathrm{cm}^{3}$.

- White matter volume, $\mathrm{cm}^{3}$.

5. Motor exam

- Up \& Go test: time in seconds that takes a person to rise from a chair, walk three meters, turn around, walk back to the chair, and sit down.

- Taps right hand: number of taps in one minute performed by opening and closing the thumb and index fingers of the right hand.

- Taps left hand: number of taps in one minute performed by opening and closing the thumb and index fingers of the left hand.

6. Lifestyle

- EuroQol-5D (EQ-5D): total score of health status (range, $-0.654-1.000$ ).

- $\quad$ Physical activity (walking, swimming, gym): (1) almost never; (2) sometimes; and (3) usually.

- Manual activity (handicrafts, bobbin lace, bricolage): (1) almost never; (2) sometimes; and (3) usually.

- Leisure activity (going to cinema, theatre, concerts, exhibitions, conferences): (1) almost never; (2) sometimes; and (3) usually.

- Creative activity (painting, drawing, writing, composing music): (1) almost never; (2) sometimes; and (3) usually.

- Social activity (going out for a walk, dancing, coffee): (1) almost never; (2) sometimes; and (3) usually.

- $\quad$ Reading (books, newspapers, magazines): (1) almost never; (2) sometimes; and (3) usually.

- Information and Communications Technology (ICT) use (computer, mobile phone, surf the web): (1) almost never; (2) sometimes; and (3) usually.

7. Diet

- Fruit consumption during the last week: (0) 0 days; (1) 1-2 days; (2) 3-5 days; and (3) 6-7 days.

- Vegetables consumption during the last week: (0) 0 days; (1) 1-2 days; (2) 3-5 days; and (3) 6-7 days.

8. Anthropometric

- Weight, kg.

- Height, $\mathrm{cm}$.

- Body Mass Index (BMI), $\mathrm{kg} / \mathrm{m}^{2}$.

We performed a preliminary analysis with the above mentioned variables to find out their distribution and potential relationships with SES. Both ISES and NSES were treated as fourlevel independent variables defined by the quartile. Upper quartile was always used as the 
reference group in the analyses. Moreover, since the percentage of females was disproportionately distributed according to ISES and NSES quartiles, the analyses were repeated separately for males and females to control for the gender effect upon the results. In all cases, associations between categorical variables were analyzed using the Pearson's $\chi^{2}$ test. The comparisons between groups were performed with the non-parametric Kruskal-Wallis tests due to the differences in sample size and to the non-adjustment to the parametric assumptions of most variables. Bonferroni correction was used in order to minimize the number of false positives when performing multiple comparisons.

\section{eResults}

eTable 1 summarizes the baseline characteristic by ISES and NSES quartiles. An expected a straight and linear trend was always found in favor of higher levels versus lower levels of SES in a large set of baseline variables of diverse nature: (1) demographics: age, education, occupation, and gender; (2) clinical: smoking, depression, and auditory deficit; (3) cognitive performance: global cognition, episodic memory, semantic fluency, processing speed, and clinical impression; (4) MRI: grey and white matter volumetry; (5) motor: up \& go and tapping with both hands; (6) lifestyle: quality of life, as well as frequency of engagement in everyday activities such as leisure, creative, social, reading, and ICT use; and (7) anthropometrics: weight, height and body mass index (BMI). These results are compatible with those already found in the literature relating high-SES with larger brain sizes,(Waldstein et al., 2017) greater thicknesses of cortical gray matter and even brain's functional network organization, (Chan et al., 2018) better cognitive performance,(Lyu \& Burr, 2016; Marden, Tchetgen Tchetgen, Kawachi, \& Glymour, 2017) and richer life-styles such as more high-quality food(Mayén, Marques-Vidal, Paccaud, Bovet, \& Stringhini, 2014) or less smoking habits.(Eibner \& Evans, 2005) The repetition of these analyses separately for males and females gave similar results indicating that gender is not a confounder factor (eTable 2 and eTable3).

There is an overlapping of the significant variables in both SES; however differences between upper and lower quartiles are greater in ISES than in NSES. eFigure 1 shows the magnitude of those differences. Moreover, while significant differences may be found between Q2 and Q3 in SES, we did not obtain so clear differences in NSES. The magnitude of the effect produced by ISES was greater for the majority of variables than that produced by NSES, except for some biological variables such as volumetry of gray and white matter, BMI and auditory deficits (eFigure 1). Moreover, differences between the four ISES quartiles were also greater than between the four NSES quartiles. These findings would suggest that there is a well-established pattern of linear trend between the four ISES quartiles but the same pattern is not found regarding the NSES quartiles. 


\section{eReferences}

1. Olazarán J, Valentí M, Frades B, et al. The Vallecas Project A Cohort to Identify Early Markers and Mechanisms of Alzheimer's Disease. Front Aging Neurosci. 2015;7:181. doi:10.3389/fnagi.2015.00181.

2. Waldstein SR, Dore GA, Davatzikos C, et al. Differential Associations of Socioeconomic Status With Global Brain Volumes and White Matter Lesions in African American and White Adults. Psychosom Med. 2017;79(3):327-335. doi:10.1097/PSY.0000000000000408.

3. Chan MY, Na J, Agres PF, Savalia NK, Park DC, Wig GS. Socioeconomic status moderates age-related differences in the brain's functional network organization and anatomy across the adult lifespan. Proc Natl Acad Sci U S A. 2018;115(22):E5144E5153. doi:10.1073/pnas.1714021115.

4. Lyu J, Burr JA. Socioeconomic Status Across the Life Course and Cognitive Function Among Older Adults. $J$ Aging Health. 2016;28(1):40-67. doi:10.1177/0898264315585504.

5. Marden JR, Tchetgen Tchetgen EJ, Kawachi I, Glymour MM. Contribution of Socioeconomic Status at 3 Life-Course Periods to Late-Life Memory Function and Decline: Early and Late Predictors of Dementia Risk. Am J Epidemiol. 2017;186(7):805814. doi:10.1093/aje/kwx155.

6. Mayén A-L, Marques-Vidal P, Paccaud F, Bovet P, Stringhini S. Socioeconomic determinants of dietary patterns in low- and middle-income countries: a systematic review. Am J Clin Nutr. 2014;100(6):1520-1531. doi:10.3945/ajcn.114.089029.

7. Eibner C, Evans WN. Relative Deprivation, Poor Health Habits, and Mortality. J Hum Resour. 2005;40(3):591-620. doi:10.2307/4129553. 
eTable 1. Baseline characteristics of the cohort by quartiles of individual and neighborhood socioeconomic status ${ }^{\mathrm{a}}$

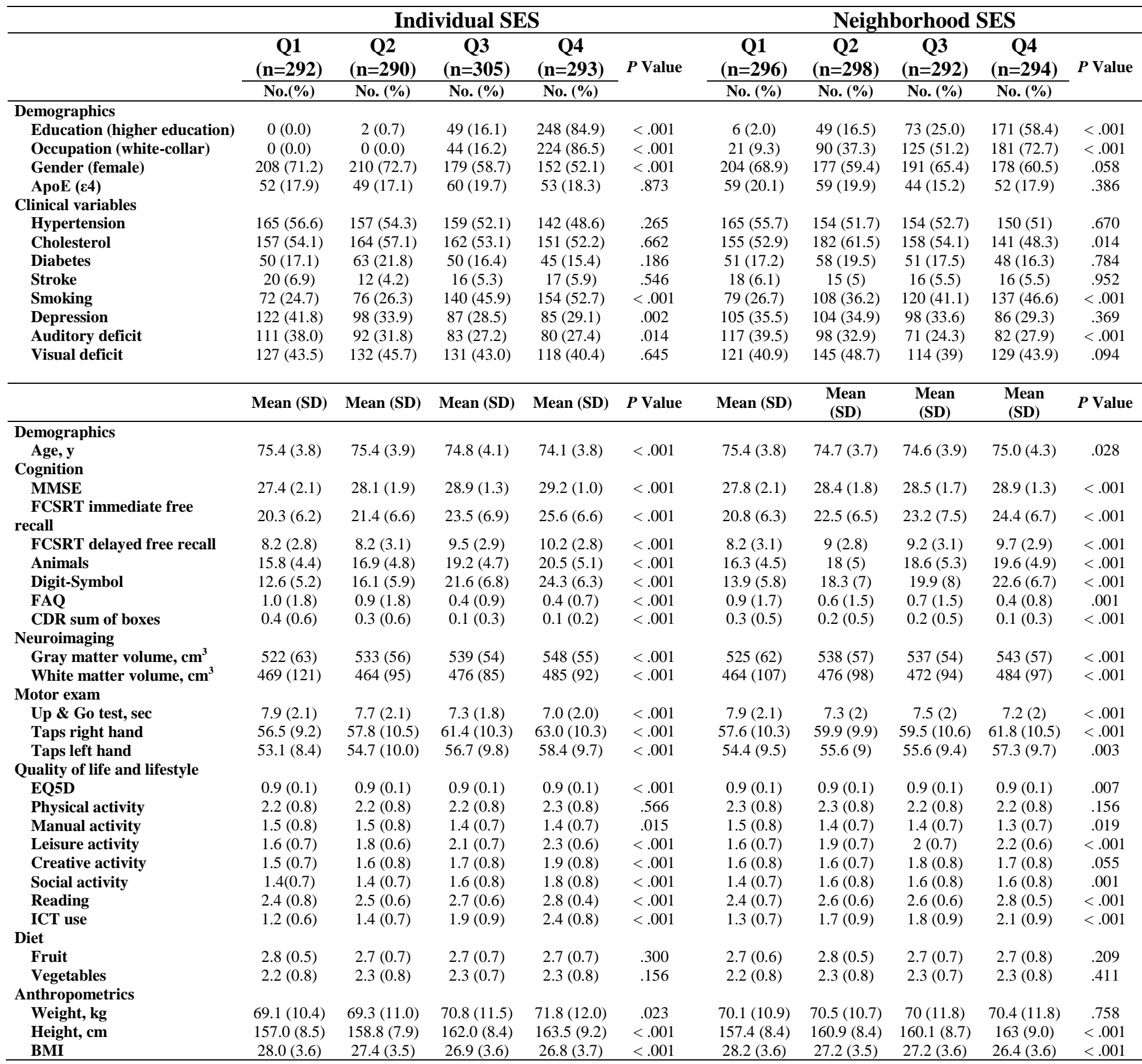

Abbreviations: BMI, Body Mass Index; CDR, Clinical Dementia Rating; EQ5D, EuroQol-5D; FAQ, Functional Activities Questionnaire;

FCSRT, Free and Cued Selective Reminding Test; ICT, Information and Communications Technology; MMSE, Mini Mental State Exam; Q, quartile.

${ }^{\text {a }}$ Quartiles follow an ordinal distribution so that the upper quartile (Q4) corresponded to the best off, while the lower one (Q1) were referred to the worst off. 
eTable 2. Baseline characteristics of males by quartiles of individual and neighborhood socioeconomic status ${ }^{\mathrm{a}}$

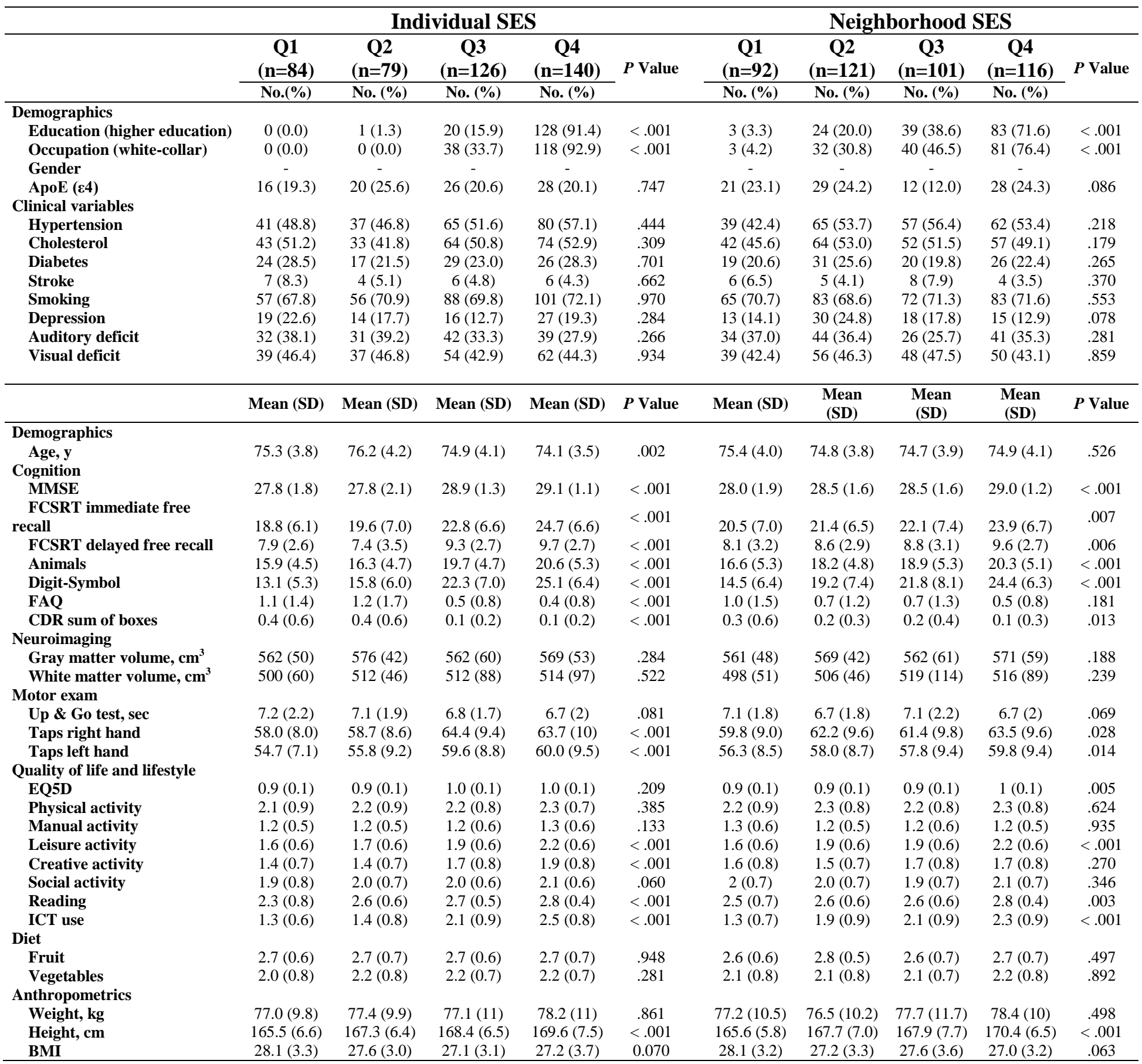

Abbreviations: BMI, Body Mass Index; CDR, Clinical Dementia Rating; EQ5D, EuroQol-5D; FAQ, Functional Activities Questionnaire;

FCSRT, Free and Cued Selective Reminding Test; ICT, Information and Communications Technology; MMSE, Mini Mental State Exam; Q, quartile.

${ }^{\text {a }}$ Quartiles follow an ordinal distribution so that the upper quartile (Q4) corresponded to the best off, while the lower one (Q1) were referred to the worst off. 
eTable 3. Baseline characteristics of females by quartiles of individual and neighborhood socioeconomic status ${ }^{\mathrm{a}}$

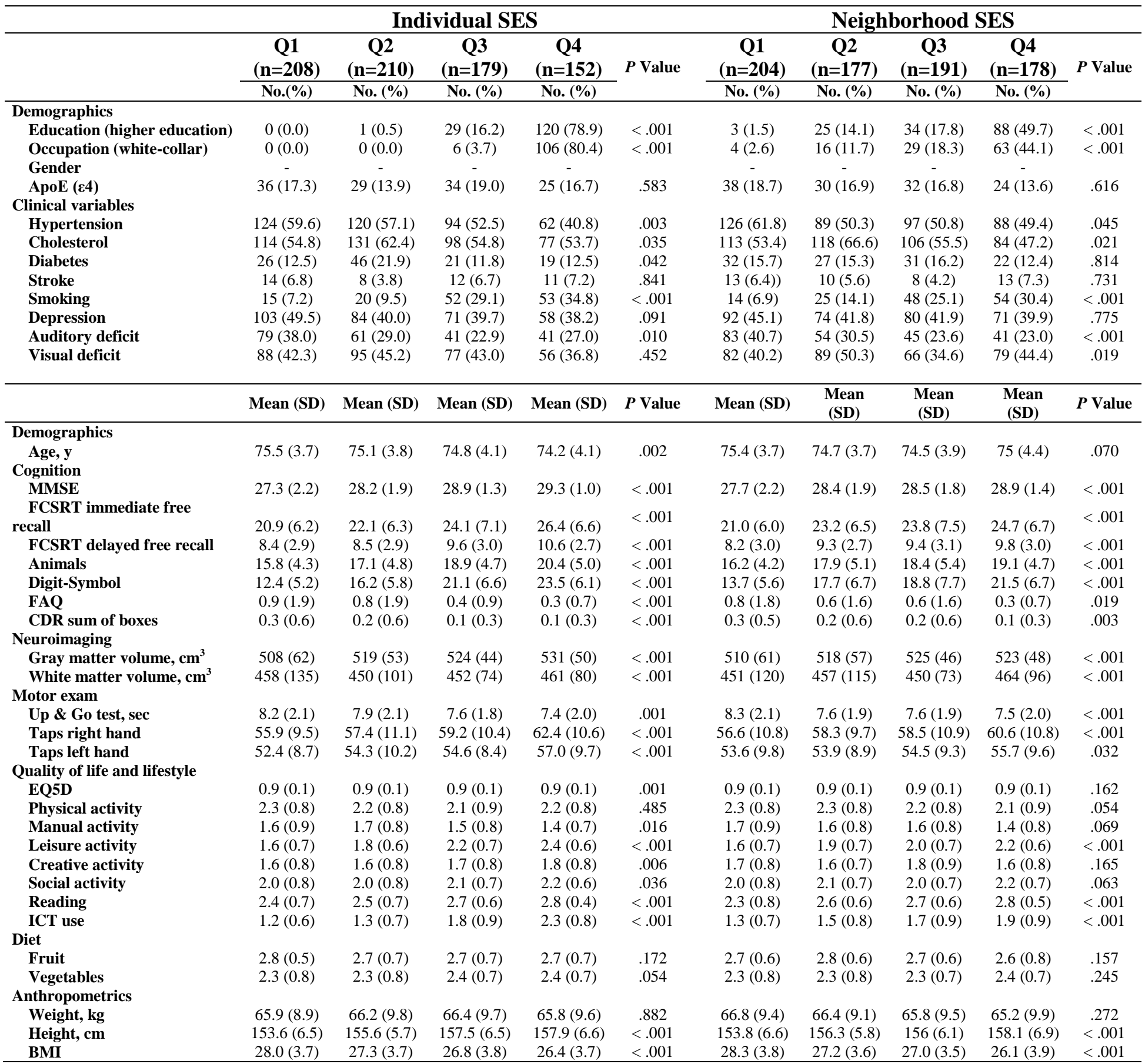

Abbreviations: BMI, Body Mass Index; CDR, Clinical Dementia Rating; EQ5D, EuroQol-5D; FAQ, Functional Activities Questionnaire;

FCSRT, Free and Cued Selective Reminding Test; ICT, Information and Communications Technology; MMSE, Mini Mental State Exam; Q, quartile.

${ }^{a}$ Quartiles follow an ordinal distribution so that the upper quartile (Q4) corresponded to the best off, while the lower one (Q1) were referred to the worst off. 


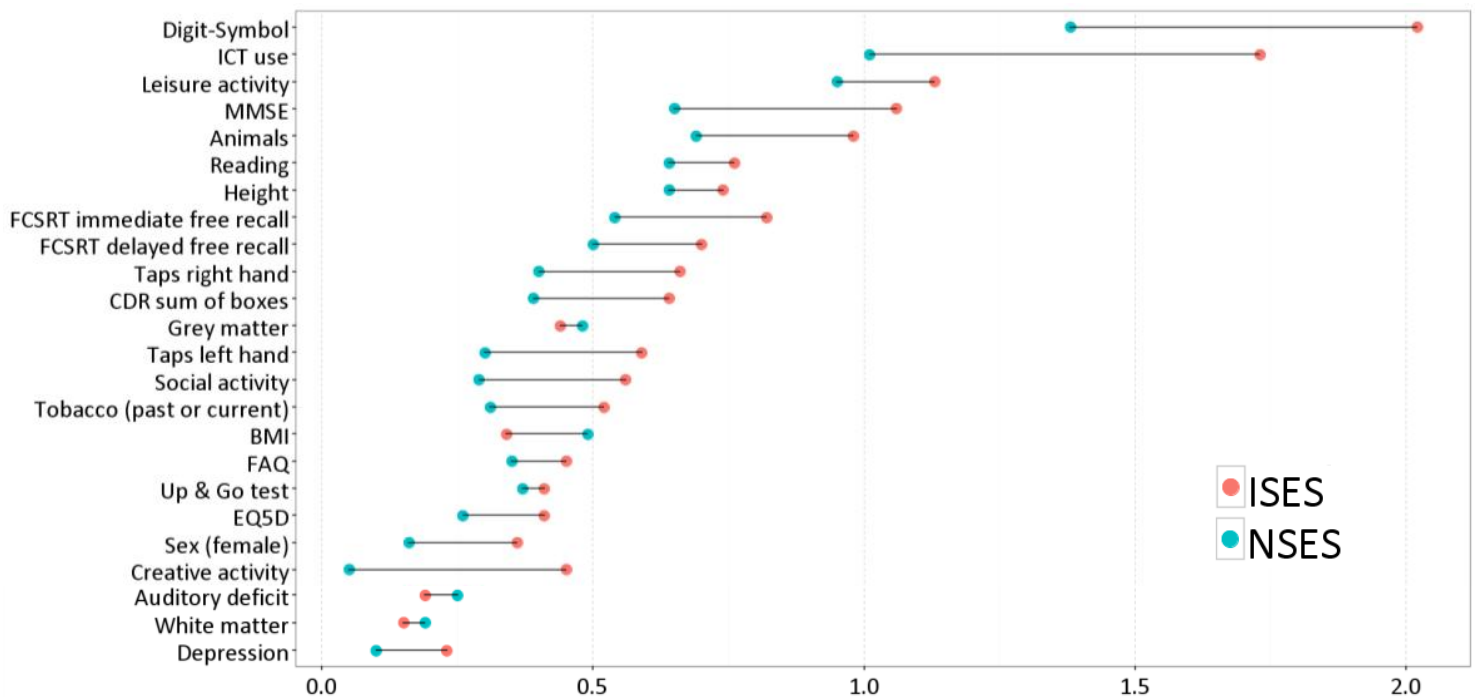

eFigure 1. Effect size of individual variables at baseline by Individual Socioeconomic Status and Neighborhood Socioeconomic Status upper and lower quartiles

Abbreviations: BMI, Body Mass Index; CDR, Clinical Dementia Rating; EQ5D, EuroQol-5D; FAQ, Functional Activities Questionnaire; FCSRT, Free and Cued Selective Reminding Test; ICT, Information and Communications Technology; ISES, individual socioeconomic status; MMSE, Mini Mental State Exam; NSES, neighborhood socioeconomic status.

This figure illustrates the magnitude of the effect in baseline individual variables according to the comparison of upper and lower quartiles of ISES and NSES. The red points represent the effect size associated with ISES, while blue points are referred to NSES. The variables are ordered from the highest to the lowest mean effect size. The Digit-Symbol test shows the greatest size effect and Depression the smallest effect. Overall, a consistent trend can be observed across the variables whereby the differences for ISES are greater than for NSES (the red dot is predominately on the right of the blue dot). The exceptions are some biological variables such as volumetry of Gray and White matter, Body Mass Index and Auditory Deficits in which effect sizes are greater for NSES. 